Corrigendum

\title{
Corrigendum to "Nutritional Status and Educational Performance of School-Aged Children in Lalibela Town Primary Schools, Northern Ethiopia"
}

\author{
Muluken Ayalew, ${ }^{1}$ Alemayehu Bayray $\mathbb{D}^{2},{ }^{2}$ Abate Bekele $\mathbb{D}^{2},{ }^{2}$ and Simegnew Handebo $\mathbb{D}^{3}$ \\ ${ }^{1}$ Lalibela Hospital, Lalibela, Ethiopia \\ ${ }^{2}$ School of Public Health, College of Health Sciences, Mekelle University, Mekelle, Ethiopia \\ ${ }^{3}$ Department of Health Education and Behavioral Sciences, Institute of Public Health, College of Medicine and Health Sciences, \\ University of Gondar, Gondar, Ethiopia
}

Correspondence should be addressed to Simegnew Handebo; hsimegnew@yahoo.com

Received 5 October 2020; Accepted 5 October 2020; Published 19 October 2020

Copyright (C) 2020 Muluken Ayalew et al. This is an open access article distributed under the Creative Commons Attribution License, which permits unrestricted use, distribution, and reproduction in any medium, provided the original work is properly cited.

In the article titled "Nutritional Status and Educational Performance of School-Aged Children in Lalibela Town Primary Schools, Northern Ethiopia" [1], author Simegnew Handebo was affiliated to the Department of Health Education and Behavioral Sciences, College of Medicine and Health Sciences, Institute of Public Health, Gondar University, Gondar, Ethiopia, which is incorrect. The correct affiliation for this author is Department of Health Education and Behavioral Sciences, Institute of Public Health, College of Medicine and Health Sciences, University of Gondar, Gondar, Ethiopia.

\section{References}

[1] M. Ayalew, A. Bayray, A. Bekele, and S. Handebo, "Nutritional status and educational performance of school-aged children in Lalibela Town primary schools, Northern Ethiopia," International Journal of Pediatrics, vol. 2020, Article ID 5956732, 9 pages, 2020. 